Research article

\title{
Callus induction and organogenesis from Tinospora formanii Udayan and Pradeep: A rare endemic plant
}

\author{
Sheema Dharmapal P. ${ }^{1}$, M. Najla ${ }^{1}$, E. S. Swetha ${ }^{1}$, P. S. Udayan ${ }^{1}$ and K. K. Elyas ${ }^{2}$ \\ ${ }^{1}$ Department of Botany, Sree Krishna College, Guruvayur, Ariyannur P.O., Thrissur-680102, Kerala, India \\ ${ }^{2}$ Department of Biotechnology, University of Calicut, Calicut University P.O., Malapuram-673635, Kerala, India \\ *Corresponding Author: sheemamohandaas@gmail.com \\ [Accepted: 16 February 2017]
}

\begin{abstract}
Tinospora is a genus within the family Menispermaceae renowned for its medicinal properties. The present study was undertaken to develop an effective protocol for optimum callus induction and organogenesis in Tinospora formanii, a rare endemic plant reported from Western Ghats of Kerala. Data of number of days required for callus induction, callus induction percentage, callus morphology, callus fresh weight and number of days required for shoot regeneration were recorded. Nodal segments from one year old plants were used as explants for callus induction and shoot regeneration. After proper treatment of explants with surface sterilants, $70 \%(\mathrm{v} / \mathrm{v})$ ethyl alcohol and $0.1 \%$ (w/v) mercuric chloride $\left(\mathrm{HgCl}_{2}\right)$, it was transferred to Murashige and Skoog's (MS) medium supplemented with different concentration of 6-Benzylaminopurine $(0.5,1.0,2.0$, 3.0 and 5.0 and $\left.8.0 \mathrm{mg} . \mathrm{L}^{-1}\right)$ with 1-Naphthaleneacetic acid $\left(0.2 \mathrm{mg} . \mathrm{L}^{-1}\right)$. All these hormonal combinations gave callus. Maximum callus induction (96\%) was observed on medium containing $1.0 \mathrm{mg} \cdot \mathrm{L}^{-1}$ 6- Benzylaminopurine (BAP) with 1-Naphthaleneacetic acid (NAA) $0.2 \mathrm{mg} . \mathrm{L}^{-1}$. Number of days taken for callus induction in this medium was $5 \pm 0.28$. Organogenic creamy brown friable callus developed. The fresh weight of the callus was $4.75 \pm 0.08 \mathrm{gm}$ after 60 days of culture. Small green shoot buds developed from this callus after 65 days of culture which developed into shoots of about $2.5-3.0 \mathrm{~cm}$ length.
\end{abstract}

Keywords: Callus - Nodal explants - Menispermaceae - Tinospora formanii.

[Cite as: Sheema DP, Najla M, Swetha ES, Udayan PS \& Elyas KK (2017) Callus induction and organogenesis from Tinospora formanii Udayan and Pradeep: A rare endemic plant. Tropical Plant Research 4(1): 71-76]

\section{INTRODUCTION}

Plant based drugs are being increasingly preferred in medical science. The medicinal properties of plants are attributed to the presence of biologically active compounds like terpenes, alkaloids, polyphenols, flavonoids etc. Several phytochemical surveys have been carried on for detecting diverse groups of naturally occurring phytochemicals. Annual growth rate between $5-15 \%$ for trade of plant based drugs and raw materials is indicative of growing demand for herbal drugs. It is therefore, necessary to select, characterize, multiply and conserve genetically superior planting material of important medicinal plants for assured uniformity and desired quality. The biotechnological tools can play an important role in selecting, multiplying and conserving the critical genotypes of species. Further, biotechnological tools and techniques offer scope for multiplication and genetic enhancement of desirable genotypes and in vitro plant cell culture systems have potential for commercial exploitation of secondary metabolites from the plant (Manisha et al. 2012).

The genus Tinospora belonging to the family Menispermaceae has about 32 species distributed in Tropical Africa, Madagascar, Asia to Australia and Pacific Islands (Kubitzki et al. 1993, Mabberley 2008). In India, the genus is represented by 4 species. Among them, 2 species Tinospora cordifolia (Willd.) Miers. ex Hook. f. \& Thoms. and T. sinensis (Lour.) Merr. are known to occur in South India. The other two species T. crispa (L.) Miers. ex Hook. f. \& Thoms. and T. glabra (Burm. f.) Merr. are reported from Northeast India and Andaman Islands (Pramanik \& Gangopadhyay 1993).

Tinospora is a genus within Menispermaceae reputed for its medicinal properties (Pathak et al. 1995). Species of the Tinospora genus have prominent roles in the traditional medicinal practices of Australia, Africa 
and Asia. The great majority of compounds isolated from Tinospora species have been furanoid diterpenes of the clerodane type, and their glycoside derivatives (Hungerford et al. 1998).

Tinospora formanii Udayan \& Pradeep, a new species of the family Menispermaceae has been reported from the Western Ghats of Thrissur district, Kerala, South India (Udayan \& Pradeep 2009). Tinospora formanii is a woody dioecious climber growing at an altitude of 500-650 m and is endemic to Kerala. Tinospora formani is allied to T. smilacina Benth. with smooth, shining, papery bark peeling off into scales and prominent leafscars. Leaves are alternate, ovate to elliptic-lanceolate, coriaceous, and glabrous with reticulation more prominent on lower surface. Female inflorescence is greenish-yellow, glabrous, stout compound elongated pseudoracemes with six petals. Drupes are globose and red when mature.

Tinospora formanii is a rare, endemic plant. Therefore, the present experiment has been designed to develop an efficient protocol for callus culture and organogenesis of $T$. formanii from nodal explants under in vitro conditions.

\section{MATERIALS AND METHODS}

Nodal explants collected from one year old vegetatively propagated disease free plants were cultured on MS media for callus initiation. The explants were first washed in running tap water for 30 minutes and then soaked in distilled water for 30 minutes. The explants were then treated with Tween 20 emulsifier solution $(0.01 \% \mathrm{v} / \mathrm{v})$ for five minutes. After distilled water wash for 2-3 times, the explants were taken to the laminar air flow chamber for further sterilization. The nodal explants were initially sterilized in ethyl alcohol (70 \%) for 30 seconds followed by $0.1 \%$ mercuric chloride for five minutes. The treated explants were then washed four times with sterile distilled water to make them free from sterilants.

Finally using sterile forceps, explants were transferred to sterile Petri dishes and the nodes were cut into vertical sections of 1.0-1.5 cm length with sterile scalpel and inoculated into the media. The nodes were then cultured on semi solid MS medium (Murashige \& Skoog 1962) supplemented with 3\% (w/v) sucrose and $0.8 \%$ (w/v) agar. The $\mathrm{pH}$ of the media was adjusted and maintained to 5.8 by using $0.1 \mathrm{~N} \mathrm{NaOH}$ or $0.1 \mathrm{~N} \mathrm{HCl}$ after the addition of growth regulators. The medium was autoclaved at $121^{\circ} \mathrm{C}, 15$ psi pressure for 15 min. All these cultures were incubated in growth room at $25 \pm 2{ }^{\circ} \mathrm{C}$ under 16 hour photoperiod at a relative humidity of 50-60 percent with a light intensity of 3000 lux provided by cool white fluorescent lamps.

Single nodal explants inoculated in each test tube having MS medium supplemented with different combinations of auxins, BAP $\left(0.5,1.0,2.0,3.0,5.0\right.$ and $\left.8.0 \mathrm{mg} . \mathrm{L}^{-1}\right)$ with NAA $\left(0.2 \mathrm{mg} . \mathrm{L}^{-1}\right)$ was used to find out a suitable concentration for callus induction and proliferation. MS without growth regulators served as control. Subcultures were done every 20 days interval into fresh medium. Observations like percentage of callus induction, number of days required for callus initiation, colour and texture of callus were recorded. To find out the growth of callus on different concentrations of above mentioned growth regulators, the callus were harvested after 60 days of initiation and measured in terms of fresh and dry weights.

The experiments were carried out in completely randomized block design and repeated three times each with 12 replications for each of the treatment. The observations were tabulated and statistical analysis was carried out, as per Sukhatme \& Amble (1985) and the results were interpreted.

\section{RESULTS}

The effect of auxins on callus initiation was studied by culturing nodal explants on MS medium supplemented with BAP and NAA in combinations. The results are summarized in table 1. It is observed that nodal segments showed highest percentage of survival when treated for 5 min with $0.1 \% \mathrm{HgCl}_{2}$. Cultures raised on basal medium (without any growth regulators) served as control. The results showed that explants failed to produce callus on hormone free medium tested for callus induction. From the results, it is clear that the concentration of $1.0 \mathrm{mg} . \mathrm{L}^{-1}$ BAP with NAA $0.2 \mathrm{mg} . \mathrm{L}^{-1}$ was optimum for callus induction. $96 \%$ of explants responded at this concentration and the callus was initiated within 5 days of inoculation (Fig. 1). After 2-3 days of inoculation, cultured explants were enlarged and became swollen, however, they remained green in colour. Then the explants were gradually covered by thin layer of cream friable callus. Callus continued to proliferate into a large mass. The maximum fresh weight observed at this concentration of phytohormones was $4.75 \pm 0.08$ gm after 60 days of culture (Table 2). Large creamy brown friable organogenic callus developed. After 65 days of culture, small green buds developed from this callus. This green bud developed into $2.5-3.0 \mathrm{~cm}$ long shoots within 14 days (Fig. 1). 
Table 1. Effect of MS media supplemented with BAP and NAA on callus induction from nodal explants of Tinospora formanii Udayan \& Pradeep.

\begin{tabular}{lccc}
\hline Treatments & $\begin{array}{c}\text { MS + Plant growth regulators } \\
\left(\mathbf{m g . L}^{-\mathbf{1}}\right)\end{array}$ & $\begin{array}{c}\text { \% of explants showing } \\
\text { callus formation }\end{array}$ & $\begin{array}{c}\text { Number of days for } \\
\text { callus induction }\end{array}$ \\
\hline $\mathrm{T}_{0}$ & MS basal (control) & 0.00 & 0.00 \\
$\mathrm{~T}_{1}$ & BAP 0.5 + NAA 0.2 & $51.0 \pm 0.92^{\mathrm{d}}$ & $18.0 \pm 1.53^{\mathrm{b}}$ \\
$\mathrm{T}_{2}$ & BAP 1.0 + NAA 0.2 & $96.0 \pm 0.95^{\mathrm{a}}$ & $5.0 \pm 0.28^{\mathrm{a}}$ \\
$\mathrm{T}_{3}$ & BAP 2.0 + NAA 0.2 & $82.6 \pm 0.69^{\mathrm{b}}$ & $19.3 \pm 0.57^{\mathrm{bc}}$ \\
$\mathrm{T}_{4}$ & BAP 3.0 + NAA 0.2 & $75.3 \pm 1.66^{\mathrm{c}}$ & $21.6 \pm 1.52^{\mathrm{cd}}$ \\
$\mathrm{T}_{5}$ & BAP 5.0 + NAA 0.2 & $26.6 \pm 3.33^{\mathrm{e}}$ & $25.0 \pm 1.33^{\mathrm{e}}$ \\
$\mathrm{T}_{6}$ & BAP 8.0 + NAA 0.2 & 0.00 & 0.00 \\
\hline
\end{tabular}

Note: Values are means \pm S.E. of three independent experiments, each consisted of 12 replicates per treatment. Treatment means followed by same letter within column are not significantly different from each other at $\mathrm{P}=0.05$; comparison by Duncan's Multiple Range Test.
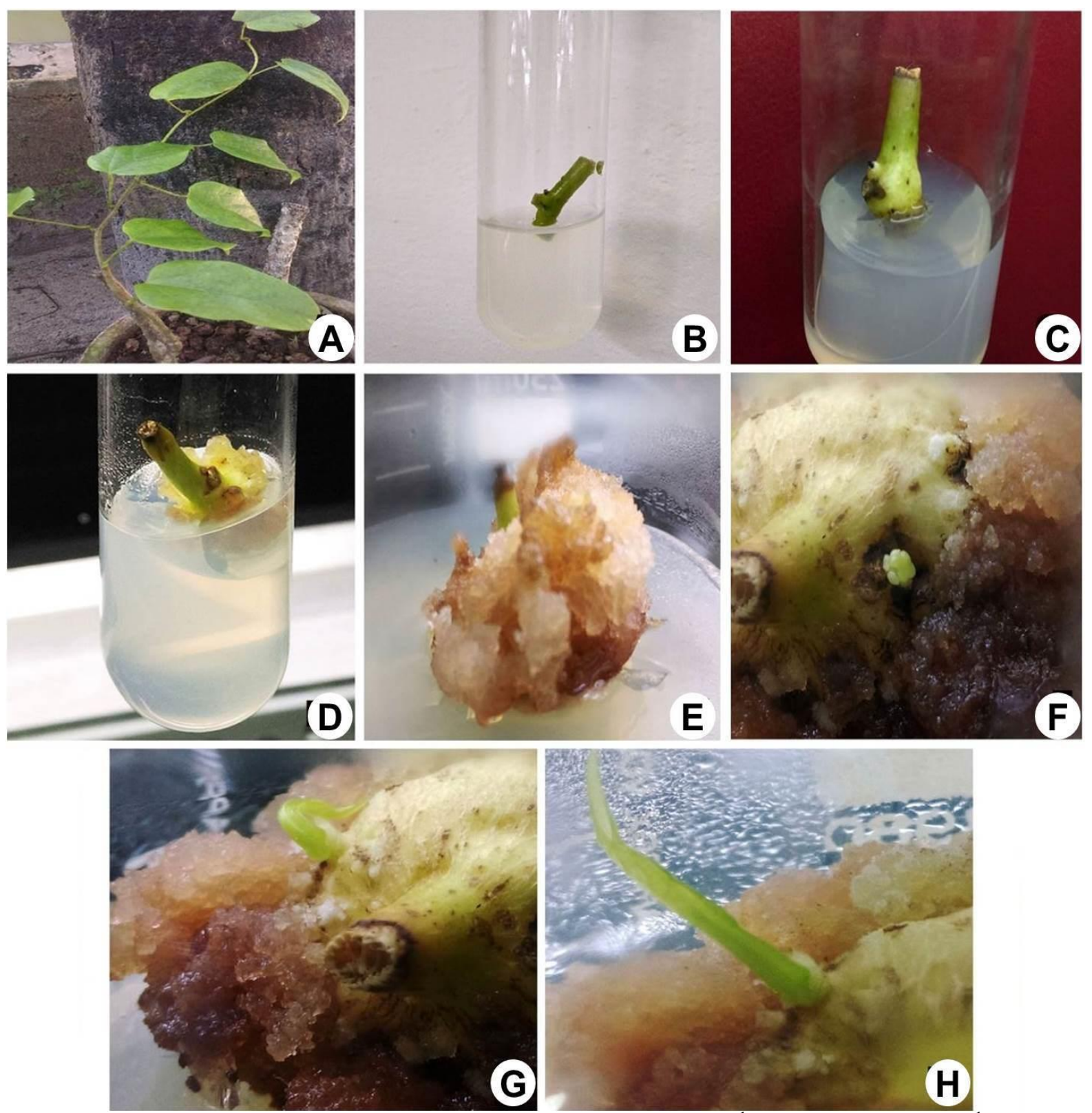

Figure 1. Callus development and organogenesis in MS supplemented with $1 \mathrm{mg} . \mathrm{L}^{-1}$ BAP and NAA $0.2 \mathrm{mg} . \mathrm{L}^{-1}$ : A, Mother plant; B, Nodal explant; C, Swelling at basal part of nodes; D, Callus initiation after 5 days of inoculation; E, Callus proliferation; F, Development of green shoot but after 65 days of inoculation; $\mathbf{G} \boldsymbol{\&} \mathbf{H}$, Shoot development from callus. 
Table 2. Fresh and dry weights of callus cultured from nodal explants of Tinospora formanii Udayan \& Pradeep on MS media supplemented with BAP and NAA.

\begin{tabular}{lccc}
\hline $\begin{array}{l}\text { MS + Plant growth } \\
\left.\text { regulators (mg. }{ }^{-1}\right)\end{array}$ & Type of callus & Fresh weight $(\mathbf{g m})$ & Dry weight (gm) \\
\hline BAP 0.5 + NAA 0.2 & Soft yellow watery & $0.87 \pm 0.01^{\mathrm{c}}$ & $0.34 \pm 0.33^{\mathrm{e}}$ \\
BAP 1.0 + NAA 0.2 & Creamy brown friable & $4.75 \pm 0.08^{\mathrm{a}}$ & $2.45 \pm 0.13^{\mathrm{a}}$ \\
BAP 2.0 + NAA 0.2 & Brown friable & $2.36 \pm 0.10^{\mathrm{b}}$ & $1.53 \pm 0.06^{\mathrm{b}}$ \\
BAP 3.0 + NAA 0.2 & Creamy yellow compact & $0.90 \pm 0.01^{\mathrm{c}}$ & $0.74 \pm 0.02^{\mathrm{c}}$ \\
BAP 5.0 + NAA 0.2 & Brown compact & $0.35 \pm 0.02^{\mathrm{d}}$ & $0.12 \pm 0.01^{\mathrm{d}}$ \\
\hline
\end{tabular}

Note: Values are means \pm S.E. of three independent experiments, each consisted of 12 replicates per treatment. Treatment means followed by same letter within column are not significantly different from each other at $\mathrm{P}=0.05$; comparison by Duncan's Multiple Range Test.

$82.6 \%$ response was obtained with $2.0 \mathrm{mg} . \mathrm{L}^{-1} \mathrm{BAP}$ and NAA $0.2 \mathrm{mg} . \mathrm{L}^{-1}$ and the callus developed after 19.3 days of inoculation in culture. At lower concentration of $0.5 \mathrm{mg} . \mathrm{L}^{-1}$ BAP with NAA $0.2 \mathrm{mg} . \mathrm{L}^{-1}$, soft yellow watery callus developed. $51 \%$ of callus initiated after 18 days of inoculation in culture medium. At higher concentrations of BAP with NAA $0.2 \mathrm{mg} . \mathrm{L}^{-1}$, compact callus was obtained. Creamy yellow compact callus developed with $3.0 \mathrm{mg} . \mathrm{L}^{-1}$ BAP and NAA $0.2 \mathrm{mg} . \mathrm{L}^{-1}$ after 21.6 days whereas brown compact callus developed with $5.0 \mathrm{mg} \cdot \mathrm{L}^{-1}$ BAP and NAA $0.2 \mathrm{mg} . \mathrm{L}^{-1}$. At higher concentration of $5 \mathrm{mg} \cdot \mathrm{L}^{-1}$ BAP with NAA $0.2 \mathrm{mg} . \mathrm{L}^{-1}$, it was observed that the number of days taken for callus initiation was increased to 25 days and the percentage of response was reduced to $26.6 \%$. At a concentration of BAP $8 \mathrm{mg} . \mathrm{L}^{-1}$ with NAA $0.2 \mathrm{mg} \cdot \mathrm{L}^{-1}$ there was no callusing (Fig. 2).
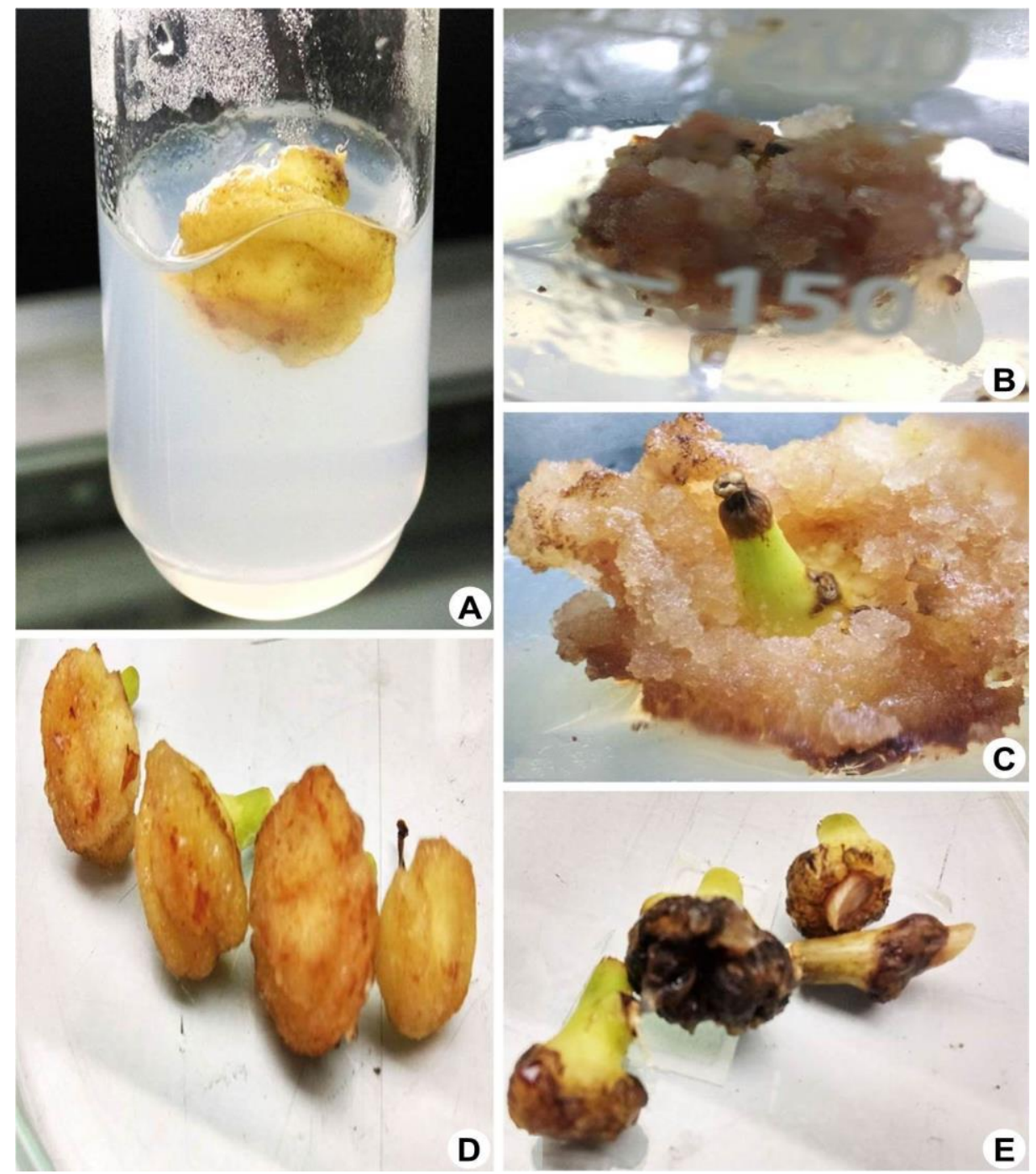

Figure 2. Different types of callus formation: A, Soft yellow watery callus; B, Brown friable callus; C, Creamy brown friable callus; D, Creamy yellow compact callus; $\mathbf{E}$, Brown compact callus. 


\section{DISCUSSIONS}

Frequency of callus induction is influenced by many factors: media composition, explant source, genotype and environment. Callusing was obtained from nodal explants on Murashige - Skoog (MS) medium supplemented with varying concentrations of BAP with NAA $0.2 \mathrm{mg} . \mathrm{L}^{-1}$. In vitro propagation in T. cordifolia was reported from nodal segments through axillary shoot proliferation (Raghu et al. 2006, Gururaj et al. 2007). Singh et al. (2009) cultured vegetative parts such as stem, leaf and nodal explants from an elite in vivo grown mature plant of Tinospora cordifolia on MS medium supplemented with different hormonal concentrations and reported callus induction and organogenesis. MS medium containing $1.0 \mathrm{mg} . \mathrm{L}^{-1}$ BAP combined with NAA 0.2 mg. $\mathrm{L}^{-1}$ was found to be optimum for callus induction in $T$. formanii. Similar findings have been reported in Tectona grandis where MS medium supplemented with $0.5 \mathrm{mg} . \mathrm{L}^{-1} \mathrm{NAA}$ and $1.5 \mathrm{mg} . \mathrm{L}^{-1}$ BAP produced compact and fibrous callus after two weeks (Egodawatta et al. 2014). Hormonal regulation of auxin and cytokinin balance is a key factor in the control of cell division in tissue culture. Media composition plays a key role in morphogenesis as nutritional requirement for optimal growth of a tissue under in vitro conditions varies with species (Bhojwani \& Rajdan 1996). The colour and texture of callus formed varied with different concentration of BAP. As reported by Roberts et al. (1984) different tissue types within the same plant or the same tissue at various stages of development produce different responses. With higher concentration of BAP, number of days taken for callus induction increased and the percentage of response decreased. Frequent sub culturing of callus was done to fresh medium to prevent browning and to enhance the survival rate. Brown exudates promote dying of cells by interfering with the metabolic activities of cells.

\section{CONCLUSION}

An efficient protocol for callus culture and indirect organogenesis of Tinospora formanii Udayan \& Pradeep was established in the present study. In vitro culture can be used to propagate and conserve such rare and endemic plants. Callus culture can be employed to reduce the over exploitation of plants from their in situ habitats and harvest secondary metabolites from rare medicinal plant. The medicinal properties of this plant are to yet be scientifically explored in a systematic way. This protocol may open a new way to facilitate secondary metabolites production and isolation of pharmaceuticals from callus without harvesting the whole plant.

\section{ACKNOWLDGEMENTS}

The authors express gratitude to UGC, Government of India for the financial support as research grant. The authors are also thankful to Dr. G. Jayakrishnan, Head of the Department, Botany, Sree Krishna College, Guruvayur for his valuable suggestions and support.

\section{REFERENCES}

Bhojwani SS \& Razdan MK (1996) Plant tissue culture: Theory and practice. Elsevier, Amsterdam.

Egodawatta WCP, Karunaratne MLWO M \& Peries SE (2014) Callus induction and organogenesis from leaf explants of Tectona grandis. Annals of Biological Research (4): 74-82.

Gururaj HB, Giridhar P \& Ravishankar GA (2007) Micropropagation of Tinospora cordifolia (Willd.) Miers ex Hook. F \& Thoms - a multipurpose medicinal plant. Current Science 92: 23-26.

Hungerford NL, Sands DPA \& Kitching W (1998) Isolation and structure of some constituents of the Australian medicinal plant Tinospora smilacina ('snakevine'). Australian Journal of Chemistry 51: 1103-1111.

Kubitzki K, Rohwer JG \& Bittrich V (1993) The families and genera of vascular plants Vol. II. SpringerVerlag, Berlin Heidelberg, Germany.

Mabberle DJ (2008) Mabberley's plant-book: A portable dictionary of the vascular plants, their classification and uses, $3^{\text {rd }}$ edition. Cambridge University Press.

Manisha M, Arun S, Anupam KM, Subhash K, Ashok C \& Ashok D (2012) Biotechnological advances in overview of present status and future prospects. Vegetos 25: 182-191.

Murashige T \& Skoog F (1962) A revised medium for rapid growth and bioassays with tobacco tissue cultures. Physiology of Plant 15: 473-497.

Pathak AK, Jain DC \& Sharma RP (1995) Chemistry and biological activities of the genera Tinospora. Pharmaceutical Biology 33: 277-287.

Pramanik A \& Gangopadhyay M (1993) Flora of India, Part 1. Botanical Survey of India, Calcutta.

Raghu AV, Geetha SP, Gerald M, Indira B \& Ravindran PN (2006) In vitro clonal propagation through mature 
nodes of Tinospora cordifolia (Willd.) Miers ex Hook F and Thoms: An important ayurvedic medicinal plant. In vitro Cellular and Development Biology - Plant 42: 584-588.

Roberts DR, Walker MA, Thompson JE \& Dumbroff EB (1984) The effect of inhibitors of polyamine and ethylene biosynthesis on senescence, ethylene production and polyamine levels in cut carnation flowers. Plant Cell Physiology 25: 315-322.

Singh A, Sah SK, Pradhan A, Rajbahak S \& Maharajan N (2009) In vitro study of Tinospora cordifolia (Willd.) Miers (Menispermaceae). Botanica Orientalis - Journal of Plant Science 6: 103-105.

Sukhatme PV \& Amble VN (1985) Chapter VIII. In: Statistical methods for agricultural workers, Revised Edition. ICAR, New Delhi.

Udayan PS \& Pradeep AK (2009) A new species of Tinospora (Menispermaceae) from South India. Edinburgh Journal of Botany 66 (1): 77-80. 